\title{
Correction to: Cadaveric surgery in core gynaecology training: a feasibility study
}

Chou Phay Lim", Mark Roberts ${ }^{2}$, Tony Chalhoub², Jason Waugh ${ }^{3}$ and Laura Delgaty ${ }^{4}$

\section{Correction}

After publication of the original article [1] it was brought to our attention that author Laura Delgaty was incorrectly included as Laura Delegate. The correct spelling of the author's name is included in the author list of this correction and updated in the original article.

\footnotetext{
Author details

'Obstetrics and Gynaecology, Royal Victoria Infirmary, Newcastle upon Tyne Hospitals NHS Foundation Trust, Newcastle Upon Tyne NE1 4LP, UK. ${ }^{2}$ Royal Victoria Infirmary, Newcastle Upon Tyne, UK. ${ }^{3}$ Obstetrics and Gynaecology, Northern Deanery, HEE (NE), Newcastle Upon Tyne, UK. ${ }^{4}$ Newcastle University, Newcastle Upon Tyne, UK.
}

Received: 5 February 2018 Accepted: 5 February 2018

Published online: 19 February 2018

\section{Reference}

1. Lim CP et al (2018) Cadaveric surgery in core gynaecology training: a feasibility study. Gynecol Surg 15:4. https://doi.org/10.1186/s10397-0171034-0

\footnotetext{
* Correspondence: chouphay.lim@nhs.net

${ }^{1}$ Obstetrics and Gynaecology, Royal Victoria Infirmary, Newcastle upon Tyne Hospitals NHS Foundation Trust, Newcastle Upon Tyne NE1 4LP, UK

Full list of author information is available at the end of the article
} 